\title{
Features of hospitalisations for acute exacerbation of COPD resulting in death
}

\author{
T. Kinnunen1, O. Säynäjäkangas², T. Keistinen³
}

ABSTRACT: Features of hospitalisations for acute exacerbation of COPD resulting in death. T. Kinnunen, $O$. Säynäjäkangas, T. Keistinen.

Background. Hospitalisation periods for the acute exacerbation phase of COPD are a strain on health facilities and entail high rates of hospital mortality. The aim of this study was to ascertain the characteristics of treatment periods resulting in death and the risk factors involved on the basis of treatment registers and death certificates.

Methods. Data on all treatment periods for persons over 44 years of age with a principal diagnosis of COPD that began as emergency admissions applying to the period 1993-2001 was gathered from the hospital treatment register maintained by the Finnish National Research and Development Centre for Welfare and Health, yielding a total of 72896 cases. Data on the deaths of the patients concerned was then obtained from Statistics Finland and those treatment periods which could be shown to have ended in death $(\mathrm{N}=2331)$ were taken to form the material for analysis. These were compared with a same number of control hospitalisation periods (not ending in death) in terms of specialisation, type and geographical location of the hospital, length of the treatment period and the occurrence of subsidiary diagnoses. Attention was also paid to the season of the year and the days of the week on which admission and death took place.

Results. The proportion of emergency admissions that ended in death was $3.2 \%$, The patients concerned having a mean age of $\mathbf{7 4 . 5}$ years for men and $\mathbf{7 5 . 0}$ years for women on admission. The mean duration of the treatment period was 11.5 days (SD 14.8), compared with 8.0 days (SD 7.9) for the controls. A subsidiary diagnosis existed in the case of $53.6 \%$ of the periods ending in death and $37.5 \%$ of the control periods. Deaths were most frequent on Fridays, 15.6\%, and least so on Tuesdays, $13.0 \%$. Where $24.2 \%$ of patients admitted on Saturdays or Sundays died during the first $\mathbf{2 4}$ hours, the figure for those admitted on weekdays was only $17.7 \%$. Altogether $62.8 \%$ of the treatment periods ending in death took place between December and May.

Conclusions.The COPD patients admitted at weekends showed the poorest survival, while concurrent diseases and protraction of the treatment period in winter and early spring increased the risk of death. Recognition of risk cases on admission could enable mortality to be reduced and allow savings in terms of costs through the intensification of treatment in these cases.

Monaldi Arch Chest Dis 2007; 67: 1, 10-14.

Keywords: Acute exacerbation, COPD, hospital mortality, hospital discharge register.

1 Ostrobothnia Hospital District, Kokkola,

2 Lapland Central Hospital, Department of Pulmonary Diseases, Rovaniemi,

3 Department of Public Health Science and General Practice, University of Oulu, Oulu, and Medical Director, Vaasa Hospital District, Vaasa, Finland.

Correspondence: Dr Tuija Kinnunen; Ostrobothnia Hospital District, Mariankatu 16-20, FIN-67200 Kokkola, Finland; e-mail: tuija.kinnunen@pp.kpnet.fi

\section{Introduction}

COPD is one of the most common causes of morbidity and mortality in the industrialised countries. In Europe $4-6 \%$ of the adult population suffers from COPD (1). According to the criteria of the British Thoracic Society and the Global Initiative for Chronic Obstructive Lung Disease, the prevalence of COPD was $5.4 \%$ and $9.4 \%$ respectively in Finland 1996 [2]. This disease was the fourth most frequent cause of death in the USA in 1997 [3] and it is predicted that by the year 2020 it will be the third most common cause of death in the world [4]. According to information taken from Statistics Finland, approximately a thousand people (20 / 100 000) have died of COPD yearly in the 1990s in Finland.

Approximately $10 \%$ of all hospitalisations are directly or indirectly attributable to COPD [5]. Acute exacerbations of COPD requiring hospital treatment are a severe strain on the health service and are responsible for at least two thirds of the total costs of treating respiratory diseases in both Europe and the USA [6]. In addition, the acute exacerbation phase entails a substantial rate of hospital mortality $[7,8]$. The recognition of serious risk factors at this stage can be of crucial importance for curtailing costs and reducing mortality. Studies on acute exacerbation of COPD have also identified various risk factors for in-hospital mortality, but have primarily focused on physiologic risk factors $[8,11]$. The uniquely comprehensive hospital registers available in Finland provide excellent opportunities to monitor the courses of diseases and subsequent mortality and also allow statistics to be compared from one year to the next. The aim of this study was to ascertain the characteristics of treatment periods ending in death and the risk factors involved on the basis of treatment registers and death certificates. 


\section{Material and Methods}

The National Research and Development Centre for Welfare and Health (STAKES) is provided with data on all patients treated in hospitals in Finland, including diagnoses, dates of admission and discharge and social security numbers. Data on all treatment periods for persons over 44 years of age with a principal diagnosis of COPD (according to International Classification of Diseases, 9th revision 1993-94 [ICD-9], codes 491, 492 and 496, and 10th revision 1995-2001 [IDC-10], codes J41, J42, J43, J44) that began as emergency admissions in the period 19932001 was gathered from the register. This gave a total of 72, 896 treatment periods after exclusion of all those lasting over 90 days. Data on the deaths of the patients concerned was then obtained from Statistics Finland and those treatment periods which could be shown in this way to have ended in death $(\mathrm{N}=2331)$ were taken to form the material for analysis. Each such case was then matched with one control case from the original data set in which the sex and year of admission were the same and the age on admission as close as possible to that of the index patient. These 2331 control patients were found from the database using the programme Visual Basic.

Each treatment period ending in death was then compared with its control in terms of the specialisation concerned and the type of hospital and its geographical location, for which purpose Finland was divided into two regions, the north, comprising the provinces of Lapland and Oulu, and the south, the rest of the country, the dividing line running approximately $100 \mathrm{~km}$ south of the Arctic Circle. Comparisons were also made in terms of the length of the treatment period, the occurrence of subsidiary diagnoses, the season of the year and the days of the week on which admission and death had occurred. The material was analysed using SPSS for Windows, the lengths of the treatment periods were compared using the paired samples $t$-test, and the Life Table statistical programme was used to assess the influence of the day of admission on survival and the length of the treatment period. Saturday and Sunday were regarded as the weekend and the others as weekdays.

\section{Results}

Of the 72,896 emergency treatment periods for acute exacerbation of COPD, $73.7 \%$ concerned men, whose mean age on admission was 72.2 years as compared with 72.0 years for the women. All in all $3.2 \%$ of the treatment periods ended in death, the mean ages on admission in these cases being 74.5 years for men and 75.0 years for women. The mean ages in the control groups were exactly the same. The main cause of death in the treatment periods ending in death was COPD in $84.8 \%$ of causes, cardiovascular disease in $5.4 \%$ and cancer in $2.1 \%$.

\section{Specialisation, type of hospital and geographical location}

Pulmonary diseases was the specialisation mentioned in connection with $39.3 \%$ of the treat- ment periods ending in death, as opposed to $37.7 \%$ of the control cases, while general medicine accounted for $26.6 \%$ and $28.2 \%$, respectively. Almost the same proportion of cases were treated at university hospitals, $19.5 \%$ of those ending in death and $19.4 \%$ of the control cases, but the geographical distribution was less even, $14.6 \%$ of the deaths being located in the north of Finland but $16.4 \%$ of the surviving cases.

\section{Length of treatment period and subsidiary diagnoses}

The mean length of the treatment periods ending in death was 11.5 days (SD 14.8), in contrast to only 8.0 days (SD 7.9) in the control cases, a highly significant difference $(p=0.000)$. When the material was divided into two age groups, below 75 years and 75 years or above, the corresponding mean lengths of the treatment period were 10.0 days (SD 12.9) in the cases ending in death and 7.1 days (SD 6.6) in the control cases for the former and 13.1 days (SD 16.2) and 8.9 days (SD 9.0), respectively, for the latter. Both of these differences were also statistically highly significant ( $p=$ 0.000 ).

Where $53.6 \%$ of the cases ending in death carried a subsidiary diagnosis, only $37.5 \%$ of the control cases did, also a highly significant difference $(p=0.000)$. In the previous treatment periods the subsidiary diagnosis was cardiovascular disease in $31.3 \%$ and cancer in $2.8 \%$ of all the subsidiary diagnoses and the corresponding percentages of the control cases were $20.5 \%$ and $0.6 \%$.

\section{Variation with season and day of the week}

The treatment periods ending in death began on a Monday more often than on any other day, $16.4 \%$ (fig. 1), while the control periods began most often on a Wednesday, $17.0 \%$. The quietest day in both groups was Saturday, $10.8 \%$ and $10.0 \%$, respectively. The deaths occurred most often on a Friday, $15.6 \%$, and least often on a Tuesday, $13.0 \%$ (fig. 1). The proportion of patients dying within 24 hours of admission was $24.2 \%$ for Saturday and Sunday admissions but $17.7 \%$ for weekday admissions (fig. 2).

The treatment periods ending in death took place between December and May in $62.8 \%$ of cases, while the $61.9 \%$ of the control patients who had died in the interval 1993-2001 had done so during the same months in $53.1 \%$ of cases.

\section{Discussion}

The Finnish hospital treatment register covers all hospitals in Finland, private and public, and has been shown to be highly reliable, with as much as a $95 \%$ congruence with patient records [9]. As only two versions of the classification of diseases were in use in 1993-2001, diagnoses can be assumed to have been fairly consistent over that time. Moreover, the diagnoses of COPD made within the Finnish healthcare system can certainly 


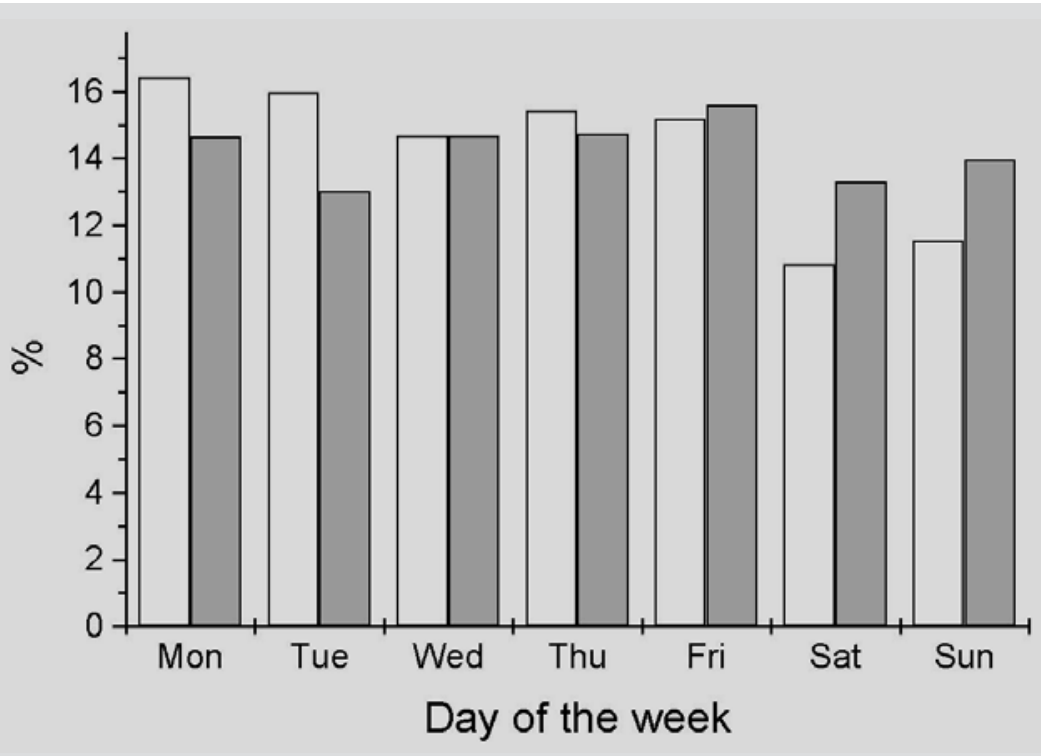

Fig. 1. - Distribution of treatment periods ending in death and control periods by day of admission (white columns) and day of death (grey columns).

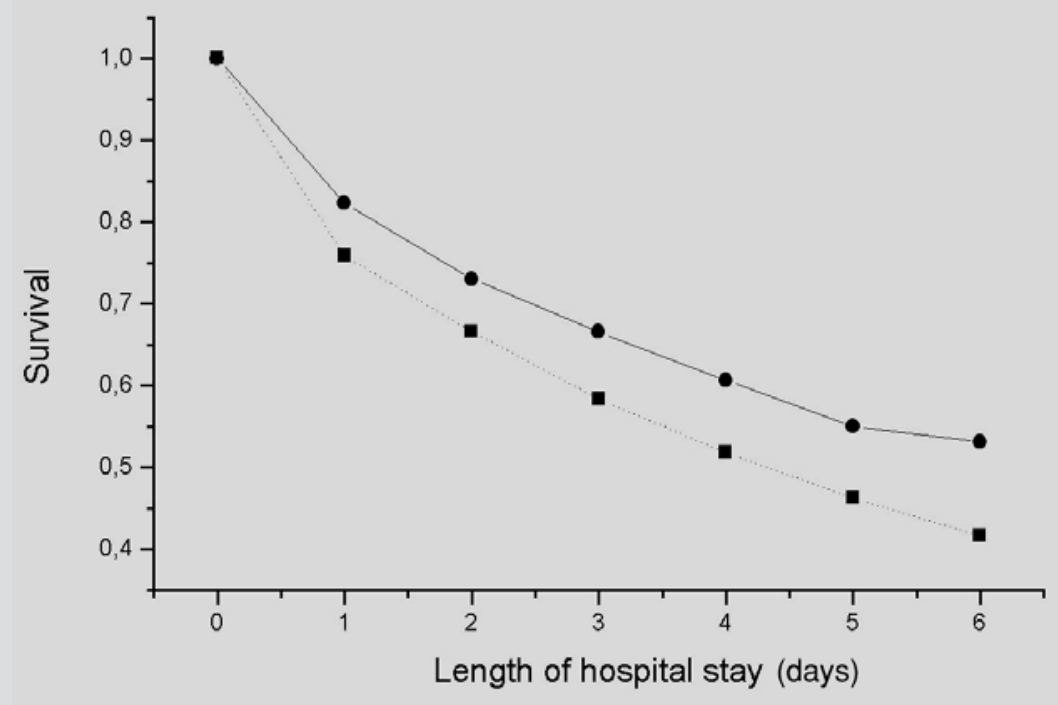

Fig. 2. - Survival of patients admitted at weekends (squares) and on weekdays (circles).

be regarded as reliable, as they are mostly made by specialists in pulmonary diseases during the whole investigation period for the purpose of entitling patients to the reimbursement of medication costs. However, changes in treatment practice and patient co-morbidity, especially treatments with other main diagnosis have perhaps influenced on the results.

Hospital mortality during the acute exacerbation phase of COPD has been reported to vary from $2.5 \%$ [10] to $14.4 \%$ [11] in different series, and our figure is much closer to the former, the material also being similar in other respects. Where patients were treated in intensive care, mortality figures ranging from $20.3 \%$ [12] to $24 \%$ [7] have been reported.

Where COPD was the cause of death in four cases out of every five of our treatment periods that ended in death, 75\% of Zielinski's patients with serious COPD had died in hospital, the most common cause of death being acute respiratory insufficiency [13].

The treatment period was slightly more apt to lead to death if it took place in a department of pulmonary diseases than with any other specialisation, presumably because the most difficult cases were assigned to such departments. Hospital mortality among COPD patients treated in the department of pulmonary diseases of a university hospital in Maastricht, Holland, is reported to have been $8 \%$, with advanced age as a significant risk factor but not the duration of treatment, nor concurrent diseases [14]. In England, hospital mortality in the exacerbation phase of COPD varied significantly according to the type of hospital, the risk being 1.56 times as great in a small hospital than in a 
teaching hospital or larger, with the resources and the number of specialists among the explanatory factors [15]. Our results nevertheless suggest that the prognosis was no better at a university hospital than elsewhere. The situation is evidently more difficult in the south of Finland than in the north, however, where a smoothly functioning healthcare system and hierarchical grading of treatment modes has been in existence for longer. The networking of services for the treatment of pulmonary diseases began in Lapland in the early 1980s [16] and continued in the 1990s under the auspices of a national programme for the prevention and treatment of respiratory distress [17].

In their study of hospital mortality and survival among patients in the acute exacerbation phase of serious COPD in the USA, Connors et al. [8] reported a mortality of $11 \%$ with a mean duration of treatment of 9 days. Our figure, for a somewhat different type of series, was very much lower and the duration of treatment longer, whereas the fact that the relative risk of death within two weeks was 1.71 for treatment periods of more 11 days but 1.0 for periods of less than three days points in much the same direction [18]. While it has been observed in Italy that cardiovascular diseases are fairly common in patients with serious COPD and tend to lead to a poorer prognosis [19], both Patil's results and our own suggest that other diseases in general increase hospital mortality among COPD patients.

The fact that patients admitted on a Saturday or Sunday tended to have a poorer prognosis than those reporting on a weekday may be linked to a shortage of pulmonary specialists on call at weekends. A young emergency department physician may be more reluctant to begin non-invasive ventilation to assist in a situation of respiratory insufficiency, which has been shown to reduce hospital mortality and improve the prognosis [20]. The same factors may also lie behind the high number of deaths on a Friday. A study of the effect of the day of the week on hospital mortality among intensive care patients in England has shown that patients admitted to the unit on a Saturday or Sunday had the highest mortality, the risk attached to Sunday admission being 1.56 relative to Wednesday, for example [21]. Another investigation in the USA has similarly shown patients admitted to intensive care at a weekend to have a significantly higher rate of hospital mortality than those taken in around the middle of the week [22].

The present observation of a higher mortality among COPD patients in winter and spring is reminiscent of the high asthma mortality in the winter months found in Finland [23] and in New Zealand [24], and also the higher rates of cardiac deaths in Canada [25] and France [26]. Apart from air pollution, the seasonal pattern of mortality from COPD may be explained by the cold winter conditions and the high incidence of respiratory infections $[27,28]$.

A treatment period for acute exacerbation of COPD was most likely to end in death if the patient was living in the south of Finland, had been admittedly to a ward for pulmonary diseases at a weekend in late winter or early spring, had other concurrent diseases and continued to need treatment for well over a week. The use of non-invasive ventilation should be increased in hospital emergency departments and wards, especially if there is inadequate response to conventional treatment [29]. This would enable treatment times to be shortened, reduce hospital mortality and achieve savings in terms of costs.

\section{References}

1. Gulsvik A. Mortality in and prevalence of chronic obstructive pulmonary disease in different parts of Europe. Monaldi Arch Chest Dis 1999; 54: 160-162.

2. Kotaniemi J-T, Sovijärvi A, Lundbäck B. Chronic obstructive pulmonary disease in Finland: prevalence and risk factors. Journal of COPD 2005; 3: 331-339.

3. Hurd S. The impact of COPD on lung health worldwide: epidemiology and incidence. Chest 2000; 117: $1 \mathrm{~S}-4 \mathrm{~S}$.

4. Viegi G, Scognamiglio A, Baldacci S, Pistelli F, Carrozzi L. Epidemiology of chronic obstructive pulmonary disease (COPD). Respiration 2001; 68: 4-19.

5. Mannino DM. COPD: epidemiology, prevalence, morbidity, and mortality, and disease heterogeneity. Chest 2002; 121: Suppl. 5, 121S-126S.

6. Wouters EF. Economic analysis of the confronting COPD survey: an over of results. Respir Med 2003; 97 : S3-14.

7. Seneff MG, Wagner DP, Wagner RP, Zimmerman JE, Knaus WA. Hospital and 1-year survival of patients admitted to intensive care units with acute exacerbation of chronic obstructive pulmonary disease. JAMA 1995; 274: 1852-1857.

8. Connors AF Jr, Dawson NV, Thomas C, et al. Outcomes following acute exacerbation of severe chronic obstructive lung disease. Am J Respir Crit Care Med 1996; 154: 959-967.

9. Keskimäki I, Aro S. Accuracy of data on diagnoses, procedures and accidents in the Finnish Hospital Discharge Register. Int J Health Sciences 1991; 2: 15-21.

10. Patil SP, Krishnan JA, Lechtzin N, Diette GB. In-hospital mortality following acute exacerbations of chronic obstructive pulmonary disease. Arch Intern Med 2003; 163: 1180-1186.

11. Fuso L, Incalzi RA, Pistelli R, et al. Predicting mortality of patients hospitalized for acutely exacerbated chronic obstructive pulmonary disease. Am J Med 1995; 98: 272-277.

12. Breen D, Churches T, Hawker F, Torzillo PJ. Acute respiratory failure secondary to chronic obstructive pulmonary disease treated in the intensive care unit: a long term follow up study. Thorax 2002; 57: 29-33.

13. Zielinski J, MacNee W, Wedzicha J, et al. Causes of death in patients with COPD and chronic respiratory failure. Monaldi Arch Chest Dis 1997; 52: 43-47.

14. Groenewegen KH, Schols AMWJ, Wouters EFM. Mortality and mortality-related factors after hospitalization for acute exacerbation of COPD. Chest 2003; 124: 459467.

15. Roberts CM, Barnes S, Lowe D, Pearson MG. Evidence for a link between mortality in acute COPD and hospital type and resources. Thorax 2003; 58: 947-949.

16. Kokkola K, Finell B, Lahdensuo A. Regional implementation of a medical care programme in Northern Finland. Community Med 1983; 5: 109-115. 
17. Laitinen LA, Koskela K. Chronic bronchitis and chronic obstructive pulmonary disease: Finnish National Guidelines for Prevention and Treatment 1998-2007. Respir Med 1999; 93: 297-332.

18. Sin DD, Tu JV. Are elderly patients with obstructive airway disease being prematurely discharged? Am $J$ Respir Crit Care Med 2000; 161: 1513-1517.

19. Antonelli Incalzi R, Fuso L, De Rosa M, et al. Co-morbidity contributes to predict mortality of patients with chronic obstructive pulmonary disease. Eur Respir $J$ 1997; 10: 2794-2800.

20. Plant PK, Owen JL, Elliot MW. Early use of non-invasive ventilation for acute exacerbations of chronic obstructive pulmonary disease on general respiratory wards: a multicentre randomised controlled trial. Lancet 2000; 355: 1931-1935.

21. Wunsch H, Mapstone J, Brady T, Hanks R, Rowan K. Hospital mortality associated with day and time of admission intensive care units. Intensive Care Med 2004; 30: 895-901.

22. Barnett MJ, Kaboli PJ, Sirio CA, Rosenthal GE. Day of the week of intensive care admission and patient outcomes: a multisite regional evaluation. Med Care 2002; 40: 530-539.

23. Harju T, Tuuponen T, Keistinen T, Kivelä S-L. Seasonal variations in hospital treatment periods and deaths among adult asthmatics. Eur Respir J 1998; 12: 13621365.

24. Kimbell-Dunn M, Pearce N, Beasley R. Seasonal variation in asthma hospitalizations and death rates in New Zealand. Respirology 2000; 5: 241-246.

25. Feldman DE, Platt R, Dery V, et al. Seasonal congestive heart failure mortality and hospitalization trends, Quebec 1990-1998. J Epidemiol Community Health 2004; 58: 129-130.

26. Boulay F, Berthier F, Sisteron O, Gendreike Y, Gibelin P. Seasonal variation in chronic heart failure hospitalizations and mortality in France. Circulation 1999; 100: 280-286.

27. Wiselka MJ, Kent J, Cookson JB, Nicholson KG. Impact of respiratory virus infection in patients with chronic chest disease. Epidemiol Infect 1993; 111: 337346.

28. Sunyer J, Saez M, Murillo C, Castellsague J, Martinez F, Anto JM. Air pollution and emergency room admissions for chronic obstructive pulmonary disease: a 5year study. Am J Epid 1993; 137: 701-705.

29. Plant PK, Owen JL, Parrott S, Elliot MW. Cost effectiveness of ward based non-invasive ventilation for acute exacerbations of chronic obstructive pulmonary disease: economic analysis of randomised controlled trial. BMJ 2003; 326: 956-960.

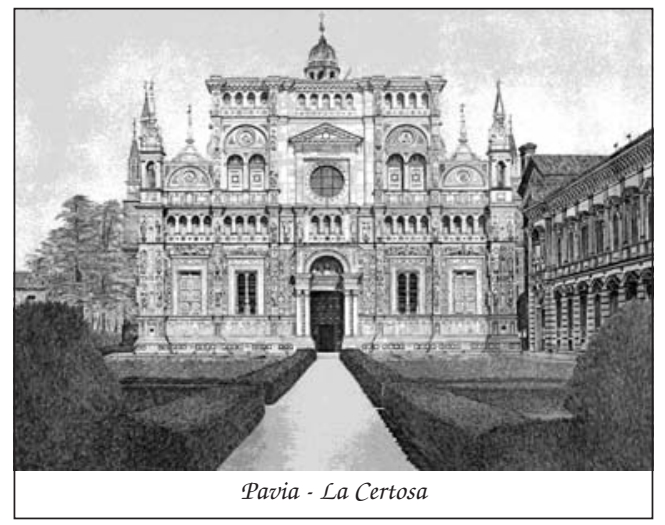

